\title{
Control Scheme for Low Voltage Ride-Through Compliance in Back-to-back NPC Converter Based Wind Power Systems
}

\author{
Salvador Alepuz ${ }^{(1)}$, Alejandro Calle ${ }^{(1)}$, Sergio Busquets-Monge ${ }^{(1)}$, Josep Bordonau ${ }^{(1)}$, Samir Kouro $^{(2)}$, Bin Wu $^{(2)}$ \\ (1) Technical University of Catalonia, Spain, ${ }^{(2)}$ Ryerson University, Canada \\ alepuz@eupmt.es
}

\begin{abstract}
The increasing influence of wind power in the power system operation has caused the power system operators to include wind power plants in the control of the overall power system, both in steady-state and transient operation. Therefore, the grid connection requirements of the power system operators involve wind power systems. Low voltage ride-through requirement is probably the most demanding grid connection requirement to meet, at least from the point of view of the wind energy conversion system. In presence of grid voltage dips, the low voltage ride-through compliance produces a mismatch between the generated active power and the active power delivered to the grid. The management of this mismatch supposes a challenge for the wind energy conversion system. In this work, a control scheme for the back-to-back neutral-pointclamped converter is proposed. Under grid voltage dip, the controllers for generator-side and grid-side converters work concurrently to meet the low voltage ride-through requirement by storing the active power surplus in the inertia of the generator and keeping constant the dc-link voltage. Simulation results verify the proposed control scheme.
\end{abstract}

\section{INTRODUCTION}

The current trend shows an increasing wind energy penetration into the grid. Actually, the total installed wind power world capacity reached $120 \mathrm{GW}$ at the end of 2008 [1]. In this context, power system operators have given response to this new scenario by updating their grid connection requirements (GCR) to ensure the reliability and efficiency of the utility. The updated GCRs include distributed generation in the operation control of the overall power system [2], [3]. Typical steady-state or quasi-stationary operation requirements such as reactive and active power regulation based on the system voltage and frequency are specified in the GCR. In transient operation, Low Voltage Ride-Through (LVRT) requirement demand wind power plants to remain connected when a grid dip occurs, contributing to keep network voltage and frequency stable by delivering active and reactive power to the grid with a specific profile depending on the grid voltage dip depth. Hence, LVRT is probably the most challenging requirement among the GCRs. All these requirements greatly affect the design of power converter and controller for a modern wind energy conversion system (WECS) [4], [5].

This work has been supported by grant 2009 BE-1 00444, Departament d'Universitats, Recerca i Societat de la Informació de la Generalitat de Catalunya (Spain) and by grant CSD2009-00046, Ministerio de Ciencia e Innovación (Spain).

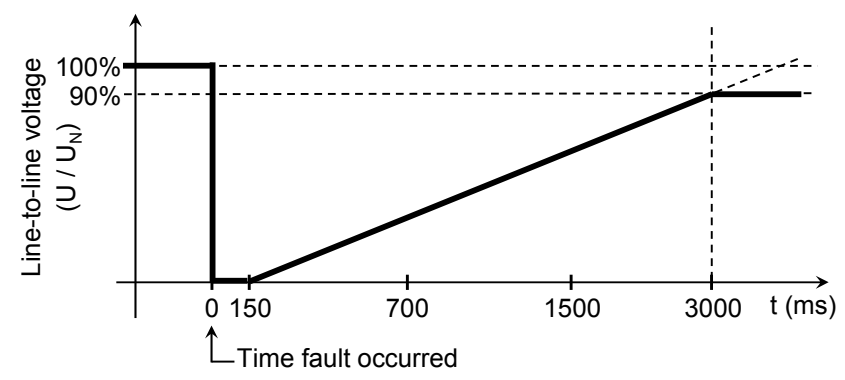

Fig. 1. Voltage limit curve to allow generator disconnection.

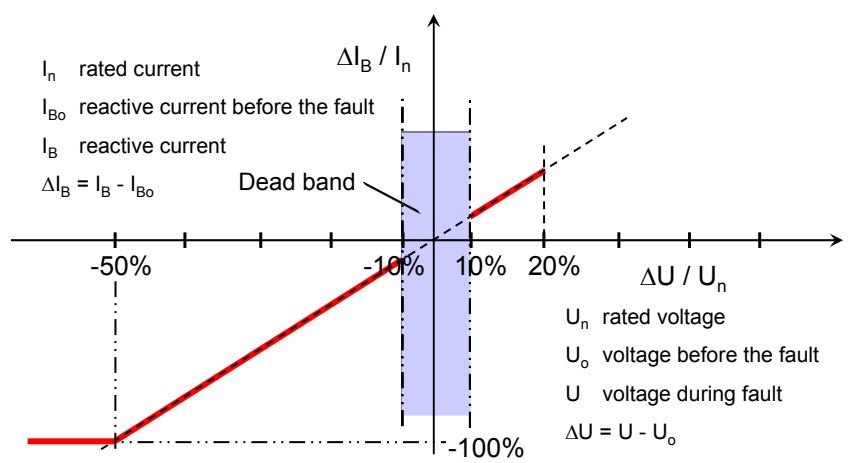

Fig. 2. Reactive current to be delivered to the grid.

LVRT requirements, extracted from the GCR of the utility operator E-ON [2], are shown in Fig. 1 and Fig. 2. When a grid dip appears, the power generation plant must remain connected to the grid if the line voltage is over the limit curve in Fig. 1. In addition, during the dip occurrence, the WECS has to deliver into the grid the amount of reactive current specified in Fig. 2; to aid the utility to hold the grid voltage. The quantity of reactive power to be injected depends on the percentage of grid voltage reduction during the dip, the system rated current, and the reactive current given to the grid before the dip appearance.

Variable-speed wind energy systems are currently preferred than fixed-speed wind turbines due to their superior wind power extraction and better efficiency. Doubly-fed induction generator (DFIG) [6], [7] is the most used implementation for variable-speed wind systems, because of the reduced power rating of the converter. Nevertheless, this topology has need of some additional circuitry to meet the LVRT requirement [5], [8], in some cases. Another common used implementation for a variable-speed wind system is based on 
a permanent-magnet synchronous generator (PMSG) with a full power converter [9], [10]. In comparison with the DFIG, this topology provides more extensive speed operating range, and full decoupling between the generator and the grid, which results in an enhanced aptitude to fulfill the LVRT requirement. These properties make this implementation interesting, even although losses also increase.

Low-voltage two-level voltage-source converters (VSCs) are the most used topology in WECS [6], [7], [9]-[11]. Considering that the current trend in WECS points to increase the power rating of the wind turbines [1], there are some topologies that can be best suited than conventional VSCs for higher power levels [4]. For instance, three-level neutral point clamped (NPC) converters [12]-[17], or current-source converters (CSCs) [4], [5].

Under grid perturbation, the maximum active power that can be injected to the grid is reduced in proportion to the terminal voltage reduction [11] and can be also limited by the LVRT requirements [2], [3]. Therefore, an active power mismatch is found between the generated power and the power delivered to the grid [15]. This is a challenge for the control system to meet the LVRT requirement.

Several methods for LVRT fulfillment are found in the literature. Dynamic braking is found in [8], [18] for the DFIG, in [11] for the two-level back-to-back VSC, and in [12], [16], [17] for the NPC back-to-back. Some different control approaches for the two-level back-to-back VSC are found in [19] and [20], but do not show how to manage the active power surplus. LVRT requirement can be achieved by storing the active power surplus in the inertia of the turbinegenerator system. This solution is found in [11] for the twolevel back-to-back VSC and in [5] for the CSC.

This work deals with the full power back-to-back NPC converter, which connects a PMSG to the grid, as shown in Fig. 3. LVRT requirement is fulfilled by storing the active power surplus in the inertia of the mechanical system. This contribution seems to be not covered in the literature. For the grid-side converter, the control approach in [15] has been used, therefore the system can manage symmetrical and asymmetrical grid dips [21].

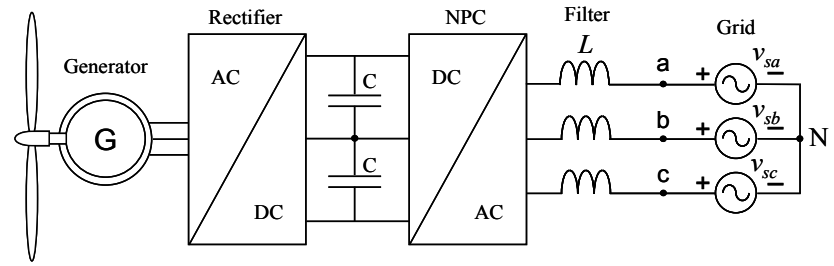

Fig. 3. Wind generator connected to the grid through a full power back-to-back NPC converter.

The paper is organized as follows: Section II details the system and its model. Control system description is given in Section III. Simulation results are found in Section IV. Finally, conclusions are formulated in Section V.

\section{SYSTEM DESCRIPTION AND MODEL}

The system considered in this work is shown in Fig. 4. Information about the dc-link neutral point is not included in the model because dc-link neutral point voltage balance is achieved by means of the space vector modulation (SVM) switching strategy [22], which is used in both NPC converters in the back-to-back topology.

\section{A. Model of the generator side}

For the generator side, the electrical equations of the PMSG are shown in (1), the torque equation in (2) and the mechanical equation in (3). Electrical and torque equations are expressed in the rotative frame $(\mathrm{dq})$, where the ' $\mathrm{d}$ ' axis is aligned with the rotor flux.

$$
\begin{gathered}
v_{s d}=R_{s} \cdot i_{s d}+L_{s} \cdot \frac{d}{d t} i_{s d}-\omega_{s} \cdot L_{s} \cdot i_{s q} \\
v_{s q}=R_{s} \cdot i_{s q}+L_{s} \cdot \frac{d}{d t} i_{s q}+\omega_{s} \cdot L_{s} \cdot i_{s d}+\omega_{s} \cdot \psi_{r} \\
T_{e}=\frac{p}{2} \cdot \psi_{r} \cdot i_{s q}
\end{gathered}
$$

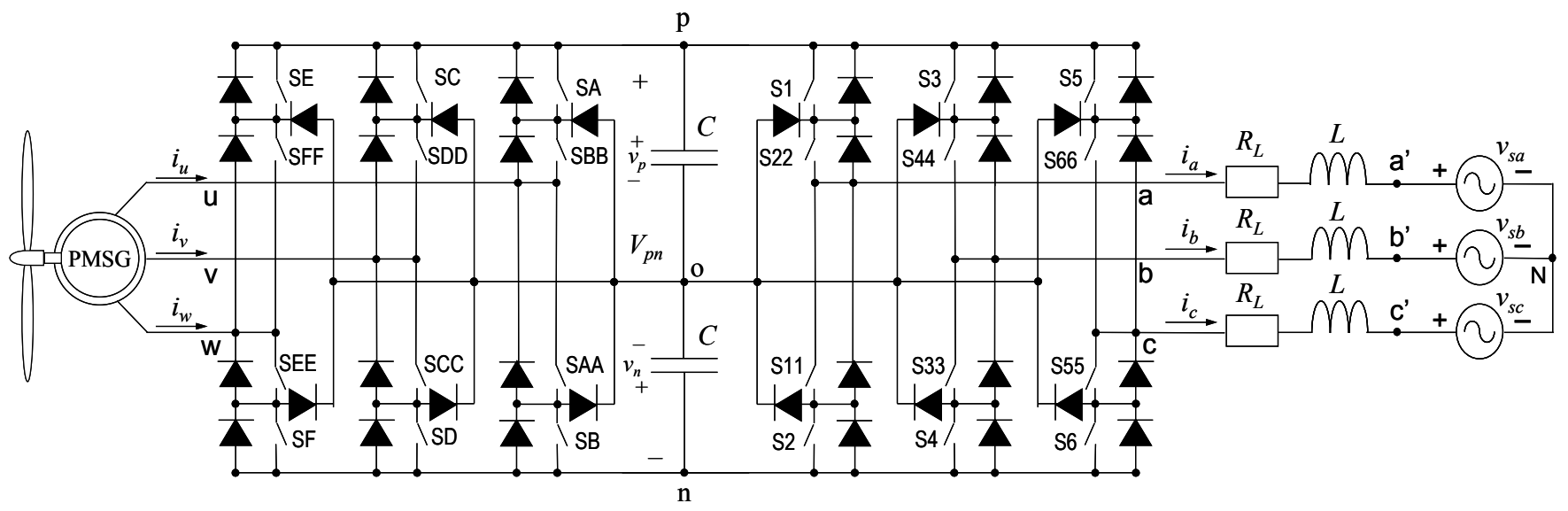

Fig. 4. PMSG connected to the grid connected to the grid through a back-to-back NPC converter and an $L$ filter. 


$$
T_{m}-T_{e}=J \cdot \frac{d \omega_{m e c}}{d t}+b \cdot \omega_{m e c}
$$

where

$\begin{array}{ll}v_{s d}, v_{s q} & \text { stator voltage in the dq frame } \\ i_{s d}, i_{s q} & \text { stator current in the dq frame } \\ L_{s} & \text { stator inductance } \\ R_{s} & \text { stator resistance } \\ \omega_{s} & \text { rotor flux electrical speed } \\ \psi_{r} & \text { rotor flux } \\ T_{e} & \text { electromagnetic torque } \\ p & \text { machine pole pairs } \\ T_{m} & \text { mechanical torque } \\ J & \text { moment of inertia of the system turbine- } \\ & \text { generator } \\ \omega_{m e c} & \text { shaft mechanical speed } \\ b & \text { friction coefficient }\end{array}$

For the implementation of the generator side control, it is needed the electrical angle of the rotor flux. This angle can be obtained by means of an encoder or by estimation from the stator voltages and currents. The rotor flux can be calculated by testing the machine with no load and measuring the electromotrice force $\left(E=\omega_{s} \cdot \psi_{r}\right)$.

\section{B. Model of the grid side}

The grid side converter has to deal with the grid dips. In [15], three different methods to deal with asymmetrical grid dips based on the use of symmetrical components have been detailed. Among these three methods, in this work, the vector current controller with feedforward of negative sequence grid voltage (VCCF) has been used. With this method, the control is implemented on the positive sequence, and there is no need to develop the negative-sequence model for the grid side converter. The sequence separation method (SSM) is used only to obtain the symmetrical components of the grid voltages. Therefore, the model for the grid side converter is shown in (4).

$$
\begin{aligned}
& \frac{d}{d t} i_{\text {dgrid }}=\omega \cdot i_{\text {qgrid }}-\frac{R_{L}}{L} \cdot i_{\text {dgrid }}+\frac{1}{L} \cdot v_{V S I d}-\frac{1}{L} \cdot v_{s d p} \\
& \frac{d}{d t} i_{\text {qgrid }}=-\omega \cdot i_{\text {dgrid }}-\frac{R_{L}}{L} \cdot i_{\text {qgrid }}+\frac{1}{L} \cdot v_{V S I q}-\frac{1}{L} \cdot v_{\text {sqp }}
\end{aligned}
$$

where:

$$
\begin{array}{ll}
i_{\text {dgrid }}, i_{\text {qgrid }} & \begin{array}{l}
\text { grid currents in the grid-dq frame } \\
v_{V S I d}, v_{V S I q}
\end{array} \\
v_{s d p}, v_{s q p} & \begin{array}{l}
\text { voltages generated at inverter terminals in } \\
\text { the grid-dq frame } \\
\text { positive-sequence grid voltages in the grid- } \\
\text { dq frame }
\end{array} \\
L & \text { filter inductance } \\
R_{L} & \text { filter resistance } \\
\omega & \text { grid pulsation }
\end{array}
$$

For system control purposes, it is required the knowledge of the phase angle of the grid. As shown in [15], to obtain it, a phase locked loop (PLL) works along with a SSM, guaranteeing angle precision when asymmetrical grid faults or unbalanced grid condition occur. The ' $d$ ' axis of the synchronous reference frame has been aligned with the positive sequence vector of the grid voltage $\left(v_{s q p}=0\right)$.

\section{CONTROL SYSTEM}

The proposed control block diagram for the system is shown in Fig. 5.

In normal operation, for the generator-side converter, the speed reference is given by some maximum power point tracking (MPPT) algorithm, to extract the maximum amount of power with the actual wind force. The MPPT algorithm has not been considered in this work. Then, the electromagnetic torque matches the mechanical torque at the speed reference, given the reference to the generator-side current $\left(i_{q}^{*}\right)$. The active power drawn from the generator is delivered to the dc-link. The dc-link regulator, in order to keep the dc-link voltage to the reference, gives the current reference ' $\mathrm{d}$ ' of the grid-side converter $\left(i_{\text {dgrid }}^{*}\right)$. Therefore, the same amount of active power drawn from the generator is delivered to the grid. On the other hand, the reactive power given/absorbed to/from the grid can be regulated by means of the ' $\mathrm{q}$ ' component of the grid-side converter current ( $\left.i_{\text {qgrid }}^{*}\right)$, independently from the active power regulation. It can be observed that the generator-side regulator controls the generator speed, and the grid-side regulator controls the dclink voltage and the reactive power flow.

Under grid voltage dip, the utility operator demands to meet the LVRT requirement. Hence, both the active and reactive power references for the grid-side converter are given by the LVRT requirement. However, the generator goes on giving active power. Then, if the generator-side converter controller does not perform any control action, during the dip the generated active power can be greater than the active power delivered to the grid. Therefore, the dc-link voltage will increase up to values that can lead to a system malfunction or even component failure. For this reason, these systems are equipped with a dc-link chopper resistor which allows to dissipate this active power surplus.

The control block diagram in Fig. 5 allows to storage the active power surplus present during the dip in the inertia of the mechanical system turbine-generator. With this control approach, the dc-link chopper resistor activation can be delayed some time. Among other factors, this delay time depends on the grid dip depth and length, the actual wind force, the actual generator speed and speed limit, and the moment of inertia of the mechanical system. Moreover, it is feasible that in most cases the dc-link chopper resistor activation will not be needed to meet the LVRT requirement. 


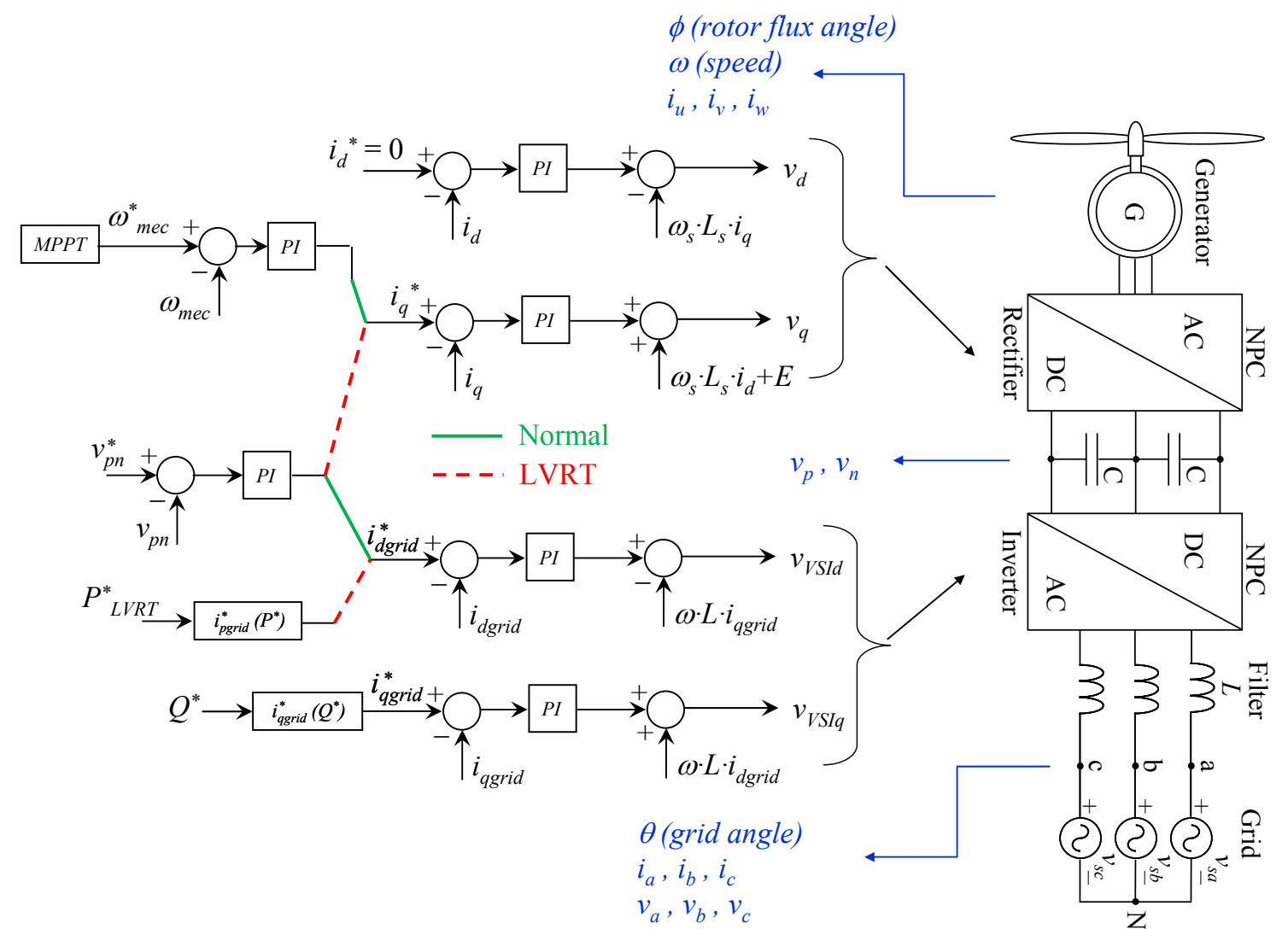

Fig. 5. Control block diagram in normal operation and under grid dip (LVRT fulfillment required), to storage the active power surplus during the dip in the inertia of the turbine-generator mechanical system.

Under grid dip, for the control block diagram in Fig. 5, the active and reactive power references to inject into the grid are given by the LVRT requirement, the dc-link voltage is controlled by the generator-side converter and the generator speed is not controlled. Under this condition, the dc-link voltage keeps regulated during the grid fault and the active power surplus is applied to the mechanical system turbinegenerator, which increases the speed.

\section{SimUlation RESUlts}

Simulation results (MatLab-Simulink) for the proposed control strategy are presented. The specifications for the system in Fig. 4 have been obtained from the experimental setup in our laboratory: $J=0.0406 \mathrm{~kg} \cdot \mathrm{m}^{2} ; L_{s}=10 \mathrm{mH} ; R_{s}=$ $0.5 \Omega ; \psi_{r}=0.382 \mathrm{~Wb} ; \mathrm{p}=4 ; L=10 \mathrm{mH} ; R_{L}=0.1 \Omega ; C=$ $2200 \mu \mathrm{F} ; V_{p n}=300 \mathrm{~V} ; V_{G R I D}=140 \mathrm{~V}_{\mathrm{RMS}} ; f=50 \mathrm{~Hz} ; T_{s}=$ $200 \mu \mathrm{s}$.

A grid voltage dip type B [21] has been simulated to show the controller performance. The grid voltage for the phase ' $a$ ' drops $60 \%$ of its nominal value during $60 \mathrm{~ms}$ (between 480 and $540 \mathrm{~ms}$ ), as depicted in Fig. 6.

Figures 6 to 14 show the simulation results if no control action is done on the generator-side controller during the dip, i.e., generator-side converter works in the same way as in steady-state, and the grid-side converter is controlled to meet the LVRT requirement.
Grid currents (Fig. 7) are balanced at any time, because of the VCCF control strategy [15] used for the grid-side converter. Instantaneous $\left(P_{G R I D}(t), Q_{G R I D}(t)\right)$ active and reactive power delivered to the grid are depicted in Fig. 8. $P$ and $Q$ references are set to $1 \mathrm{~kW}$ and $0 \mathrm{VAR}$ in steady-state. During the dip, the $P$ and $Q$ references are properly changed $\left(P^{*}=0 \mathrm{~W} ; Q^{*}=1.5 \mathrm{kVAR}\right)$ to meet the LVRT requirement. The oscillations of the instantaneous power around the power average value are inherent with the VCCF method [15]. Generator-side controller keeps its regulation unaltered, therefore there are no changes in the torque (Fig. 9), speed (Fig. 10), power drawn (Fig. 11) and currents (Fig. 12). The active power mismatch in the dc-link during the dip causes the dc-link voltage to increase (Fig. 13), which can be unacceptable, particularly if the dip length is long. Dc-link is kept balanced (Fig. 14) by means of the switching strategy. After the fault clearance, the dc-link voltage recovers by injecting more active power to the grid than the generated.

Figures 15 to 23 present the simulation results when the block diagram of Fig. 5 is used when a dip appears. The gridside converter control reacts to meet the LVRT requirement, as shown in Fig. 16 for the grid currents and in Fig. 17 for the power delivered to the grid.

In this case, the main differences are observed in the generator-side control. Under dip condition, the dc-link voltage control is assumed by the generator-side converter. 


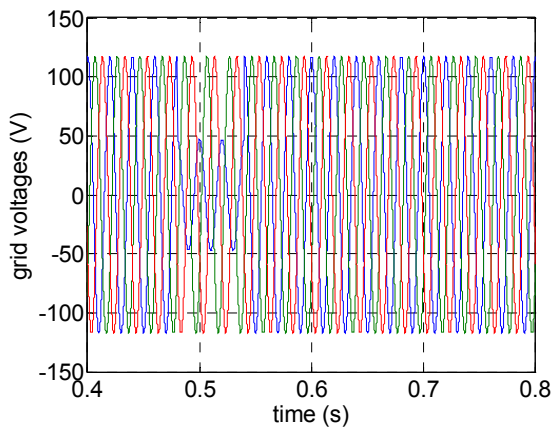

Fig. 6. Grid voltages.

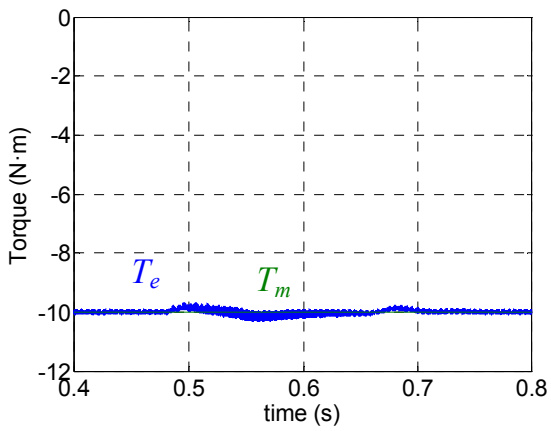

Fig. 9. Mechanical and electromagnetic torque

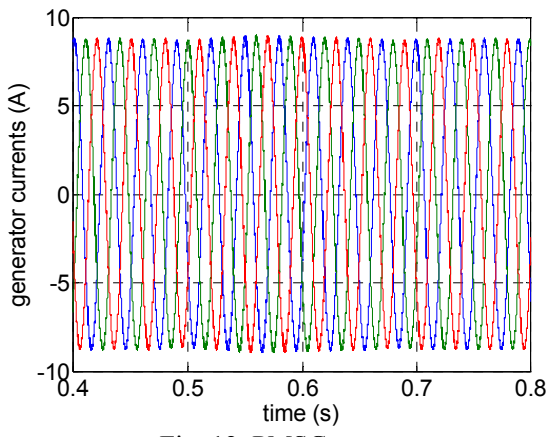

Fig. 12. PMSG currents.

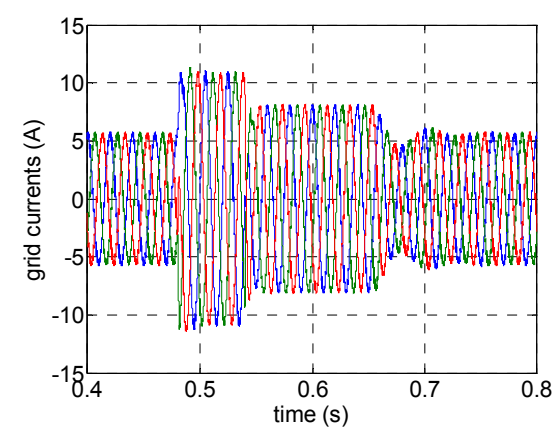

Fig. 7. Grid currents

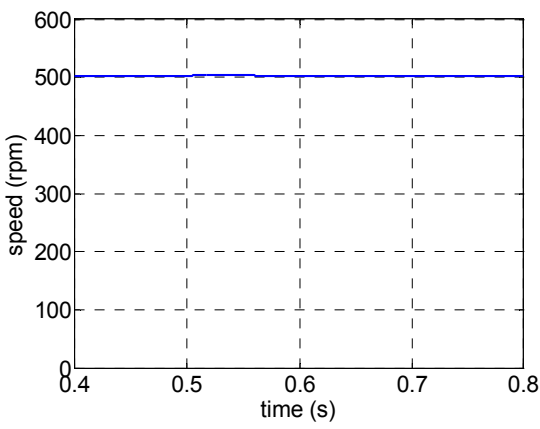

Fig. 10. Shaft speed.

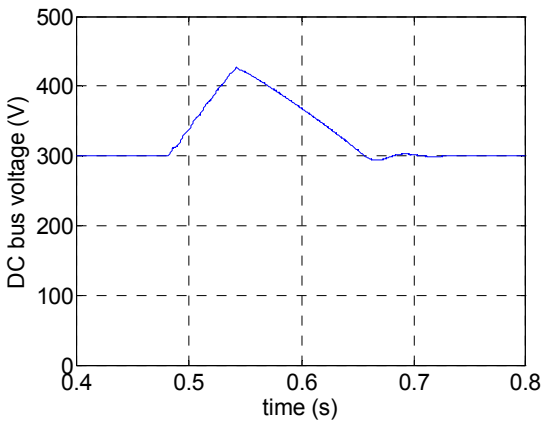

Fig. 13. Dc-link voltage.

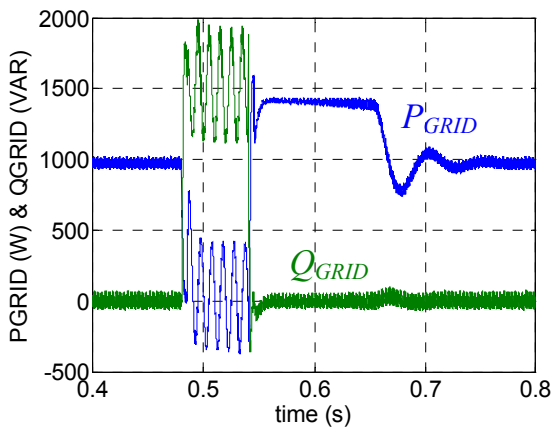

Fig. 8. Active and reactive grid power.

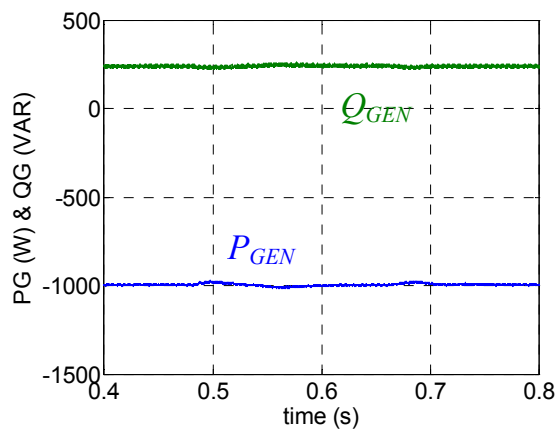

Fig. 11. Active and reactive generator power.

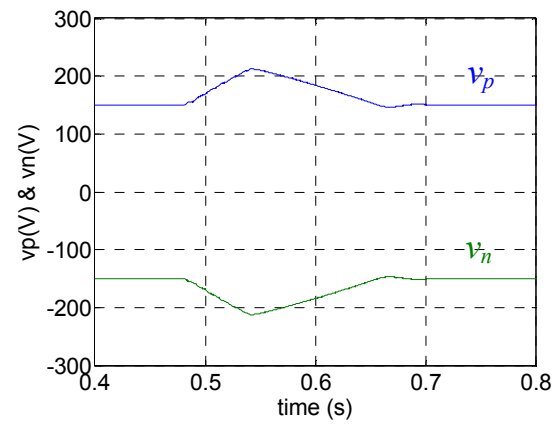

Fig. 14. Dc-link capacitor voltages.
During the dip, there is no active power injected to the grid, as result of the LVRT requirement. Therefore, in order to control the dc-link voltage, the dc-link voltage controller forces the generator to reduce the active power extracted to zero (Fig. 20). Hence, the electromagnetic torque is reduced also to zero (Fig. 18), and also the generator current (Fig. 21). Therefore, the dc-link voltage is kept at its reference value (Fig. 22). The dc-link voltage deviation is caused mainly because of the controller swap after the dip appearance and clearance. As a consequence, there is a torque mismatch in the mechanical system turbine-generator, that causes the speed to increase (Fig. 19).

After the dip clearance, the generator-side converter recovers the speed control and the grid-side converter the dclink voltage control. Speed is recovered to the reference by an electromagnetic torque greater than the mechanical torque, and the energy stored in the inertia is delivered to the grid.

\section{CONCLUSIONS}

A control approach has been presented to fulfill the LVRT requirements in a wind energy generation system based on a permanent magnet synchronous generator connected to the grid with a NPC back-to-back full converter power converter. The control allows the energy storage of the excess power present during the dip in the inertia of the turbine-generator system. Simulation results confirm the feasibility of the proposed controller.

\section{REFERENCES}

[1] Wind Energy Barometer European Commission 2009. Systèmes Solaires - Le journal de l'éolien, No. 4, pp. 45-79, Feb. 2009.

[2] Grid Code: High and extra high voltage. E. ON Netz GmbH. April, 2006. www.eon-netz.com. Germany.

[3] Red Eléctrica. Procedimiento de operación P.O. 12.3: Requisitos de respuesta frente a huecos de tensión de las instalaciones de producción en régimen especial. Oct. 2006. www.ree.es. Spain.

[4] J. Dai, D. Xu, and B. Wu, "A Novel Control Scheme for CurrentSource-Converter-Based PMSG Wind Energy Conversion Systems," IEEE Trans. on Power Electr., Vol. 24, No. 4, pp. 963-972, Apr. 2009.

[5] J. Dai, D. Xu, B. Wu, N. R. Zargari, "A unified dc link current control scheme for grid fault ride-through in current source converter based wind energy conversion systems". IEEE Energy Conv. Congress and Exp. (ECCE), pp. 1383 - 1390, San José (CA), USA, 20-24 Sept. 2009.

[6] J. Yao et al., "An improved control strategy of limiting the DC-link voltage fluctuation for a doubly fed induction wind generator". IEEE Trans. on Power Electron., Vol. 23, No. 3, pp. 1205-1213, May 2008. 


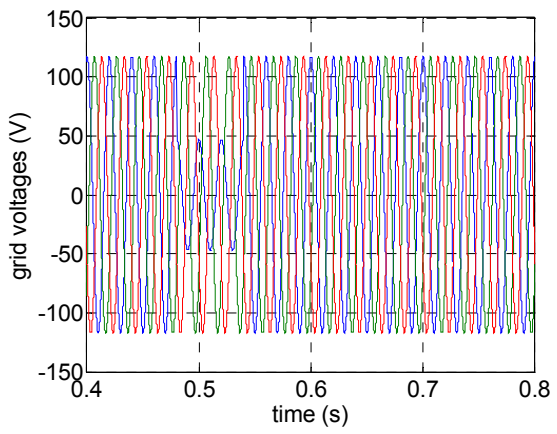

Fig. 15. Grid voltages.

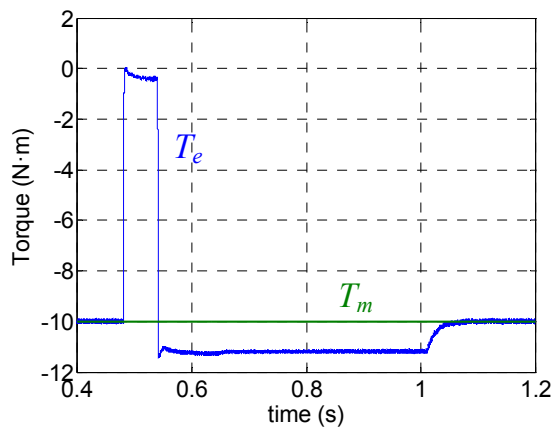

Fig. 18. Mechanical and electromagnetic torque.

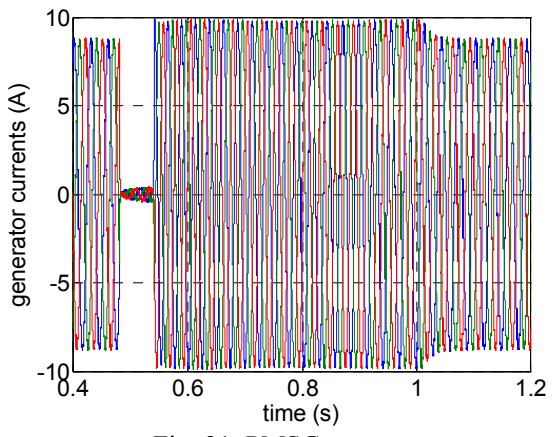

Fig. 21. PMSG currents.

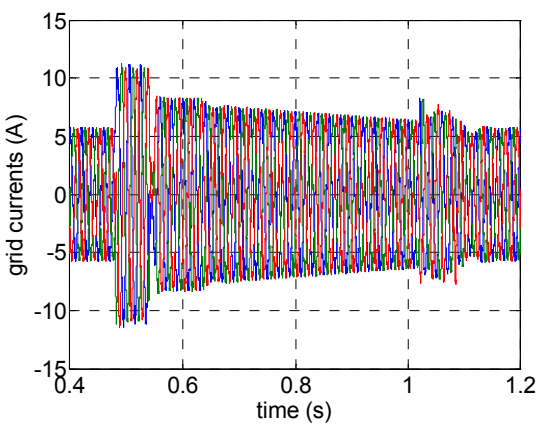

Fig. 16. Grid currents.

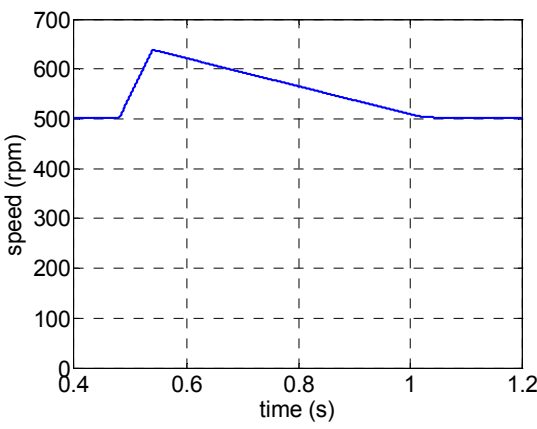

Fig. 19. Shaft speed.

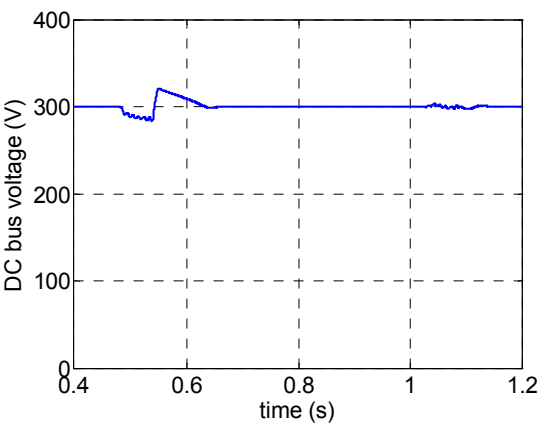

Fig. 22. Dc-link voltage.

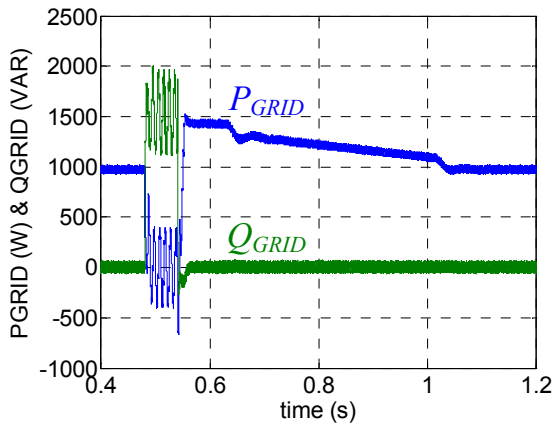

Fig. 17. Active and reactive grid power.

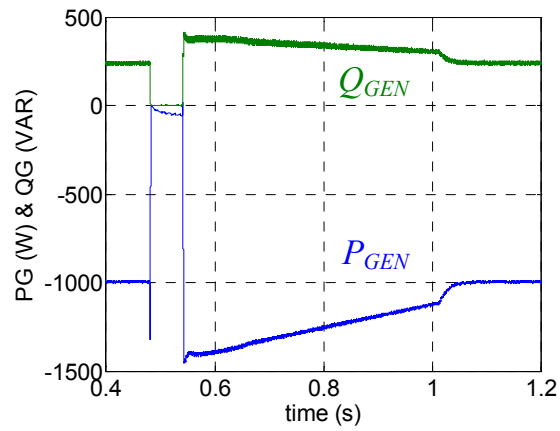

Fig. 20. Active and reactive generator power.

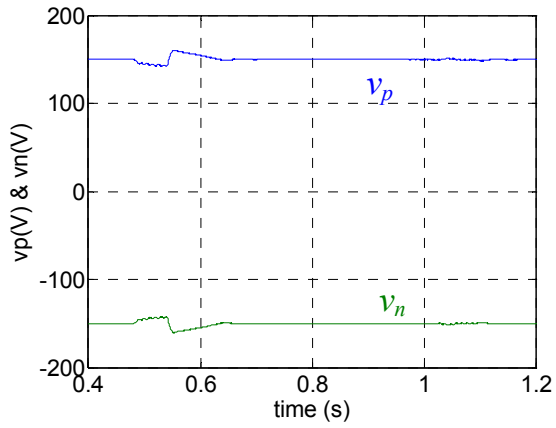

Fig. 23. Dc-link capacitor voltages
[7] L. $\mathrm{Xu}$ and $\mathrm{P}$. Cartwright, "Direct active and reactive power control of DFIG for wind energy generation". IEEE Transactions on Energy Conversion, Vol. 21, No. 3, pp. 750-758, Sep. 2006.

[8] J. Morneau, C. Abbey, and G. Joos, "Effect of Low Voltage Ride Through Technologies on Wind Farm". IEEE Canada Electrical Power Conference (EPC'07), pp. 56-61, Montreal, Canada, 25 - 26 Oct. 2007.

[9] M. Chinchilla, S. Arnaltes, J.C. Burgos, "Control of Permanent-magnet Generators Applied to Variable-Speed Wind-Energy Systems Connected to the Grid". IEEE Trans. on Energy Conversion, Vol. 21, No. 1, Mar. 2006.

[10] S. Grabic, N. Celanovic, and V. A. Katic, "Permanent magnet synchronous generator cascade for wind turbine application". IEEE Trans. On Power Electron., Vol. 23, No. 3, pp. 1136-1142, May 2008.

[11] J. F. Conroy, R. Watson, "Low-Voltage Ride-Through of a Full Converter Wind Turbine with Permanent Magnet Generator". IET Renewable Power Generation, Vol. 1, No. 3, pp. 182 - 189, Sept. 2007.

[12] A. Faulstich, J. K. Steinke, F. Wittwer. "Medium Voltage Converter for Permanent Magnet Wind Power Generators up to $5 \mathrm{MW}$. 11th European Conference on Power Electronics and Applications EPE'05. 11 - 14 Sept. 2005, Dresden, Germany.

[13] A. Yazdani and R. Iravani, "A neutral-point clamped converter system for direct-drive variable-speed wind power unit". IEEE Transactions on Energy Conversion, Vol. 21, No. 2, pp. 596-607, Jun. 2006.

[14] J. Carrasco et al., "Power-Electronic Systems for the Grid Integration of Renewable Energy Sources: A Survey". IEEE Transactions on Industrial Electronics, Vol. 53, No. 4, pp. 1002-1016, Aug. 2006.
[15] S. Alepuz, S. Busquets-Monge, J. Bordonau, J.A. Martinez-Velasco, C. Silva, J. Pontt, J. Rodriguez, "Control Strategies Based on Symmetrical Components for Grid-Connected Converters Under Voltage Dips". IEEE Trans. on Ind. Electr., Vol. 56, No. 6, pp. 2162-2173, Jun 2009.

[16] M. Eichler, P. Maibach, A. Faulstich, "Full Size Voltage Converters for 5MW Offshore Wind Power Generators". European Wind Energy Conference \& Exhibition. EWEC'08. Poster 161. 31 Mar-3 Apr, 2008.

[17] P. Maibach, A. Faulstich, M. Eichler, S. Dewar, "Full-Scale MediumVoltage Converters for Wind Power Generators up to 7 MW", Asea Brown Boveri (ABB). Feb. 2007. www.abb.com. Switzerland.

[18] A. Causebrook, D. J. Atkinson, and A. G. Jack, "Fault Ride-Through of Large Wind Farms Using Series Dynamic Braking Resistors". IEEE Trans. on Power Sys., Vol. 22, No. 3, pp. 966-975, Aug. 2007.

[19] A. Mullane, G. Lightbody, and R. Yacamini, "Wind-Turbine Fault Ride-Through Enhancement". IEEE Transactions on Power Systems, Vol. 20, No. 4, pp. 1929-1937, Nov. 2005.

[20] M. Fatu, C. Lascu, G. D. Andreescu, R. Teodorescu, F. Blaabjerg, I. Boldea, "Voltage Sags Ride-Through of Motion Sensorless Controlled PMSG for Wind Turbines". IEEE Ind. Appl. Conf. IAS'07. Vol. 1, pp. 171 - 178, 23-27 Sept. 2007.

[21] M.Bollen, Understanding power quality problems: voltage sags and interruptions, IEEE Press, 1999.

[22] S. Busquets-Monge. "A novel pulsewidth modulation for the comprehensive neutral-point voltage control in the three-level threephase neutral-point-clamped dc-ac converter". Ph. D. Dissertation. Tech. Univ. Catalunya, Spain. Feb. 2006. 